\title{
ISLAM
}

\section{DAN KONSERVASI SUMBER DAYA ALAM}

\author{
Oleh : Eko Budi Minamo
}

D "an Dialab yang menciptakan langit dan bumi dalam enam masa, dan adalab ArasyNya di atas air, agar Dia menguii siapalab diantara kamu yang lebib baik amalnya.. "Q. S. Hud :7). "Sesunggubnya Tuban kamu ialab Allab, yang menciptakan enam masa, kemudian Dia bersemayam di atas Arasy untuk mengatur segala urusan'YQ.S. Yunus : 3). Beberapa ayat tersebut memberikan penegasain tentang alam semesta ciptalan Allah. Melalui kuasa Allah Yang Maha Pencipta, terjadilah alam semewsta ini yang terdiri langit, buni clan seisinya, yakni matahari, bulan, bintang, tumbuhan, hewan, dan sebagainya yang merupakan Sumber Daya Alam (SDA). Segala SDA yang terseclia di bumi, disediakan untuk menunjang tugas manusia sebagai khalifah dimuka bumi ini. Sebagaimana statemen Allah clalam Q.S Al-Baqąah;29 "Dan Allab menjadikan segala yang ada dimuka bumi uniuk kamu dan Dia berkebendak (menciptakan) langit, lalu dijadikannya tujub langit!

Dan dengan sering
mengabaikan kebutuhan
makhluk. hidup yang lain
maupun kebutuhan generasi
yang akan datang, Kalau
kemudian muncul krisis
sehubungan dengan SDA ini,
yang terkena dampak negatif
akhirnya manusia juga. Dalam
bahasa Jawa dikatakan sebagai
ngunduh wohing pakarti
(menerima hasil perbuatannya
sendiri).

ekologis, yang menyebabkan terjadinya pergeseran keseimbangan bahkan kerusakan tatanan di bumi ini.

Tak ayal lagi, pergeseran keseimbangan tersebut secara akumulatif berdampalk munculnya krisis. Di antara berbagai krisis, yang cukup mengkhawatirkan adalah mulai terjaclinya kelangkalan beberapa Sumber Daya Alam (SDA) terutama clari kelompok yang tidak terpulihkan seperti minyak bumi, logam, dan mineral. Beberapa estimasi yang sempat muncul adalah berubahnya posisi beberapa negara penghasil minyak pada tahun 2010 menjadi negara pengimpor minyak. paclahal, minyak bumi merupakan sumber energi utama diclunia salat ini. Bagaimana hal ini clapat terjadi? Apakah hal ini merupakan clampak tinclakan manusia berkaitan dengan penggunalan SDA atau akibat langsung clari laju pertumbuhan pencluduk yang ticlak terkendalikan?

Pada awalnya, SDA seperti air, tanah, tumbuhan dan hewan hanya dimanfaatklan untuk sekeclas Dan Dia Miengetabui segala sesuatu".

Di sisi lain Allah juga memberikan statemen tentang keseimbangan atas segala ciptalanNya. Q.S. Al-Mulk:3 "Kamu sekali-kali tidak melibat pada ciptaan Tuban Yang Maba Pemurab sesuatu yang tidak seimbang": Ayat ini merupakan ayal yang sungguh luar biasá clalam kajian ekologi, clan clapat dikatakan sebagai Kaidah Utama Ekologi. Mengapa demikian? Sebab pacla awalnya diciptakan keseimbangan di alam semesta ini, mulai bersifat makro sampai ke hal-hal yang bersifat mikro. Hanya oleh perbuatan manusia sendiri yang sering hanya berorientasi pacla kepentingan ekonomis, bukan memenuhi kebutuhan primer mariusia, sehingga pemanfaatan SDA ticlak sampai mengganggu lingkungannya. Berbeda dengan saat ini, di mana penggunalan SDA ticlak sekeclar hanya untuk memenuhi kebutuhan primer melainkan juga untuk memenuhi kebutuhan-kebutuhan lainnya. Akhirnya yang terjacli aclalah eksploitasi SDA dari lingkungan secala berlebih-lebihan melampaui kemampuan bomoestatis lingkungan, clan dengan sering mengabaikan kebutuhan makhluk hiclup yang lain maupun kebutuhan generasi yang akan datang. Kalau kemudian muncul krisis sehubungan dengan SDA ini, yang terkena dampak negatif akhirnya manusia juga. 
Dalam bahasa Jawa dikatakan sebagai ngundub u'ohing pakarti (menerima hasil perbuatannya sendiri). Allah S.W.T sebenarnya telah memperingatkan ulah manusia yang tidak terpuji terhadap lingkungan dalam Surat Ar Ruum 41: Telab nampak kerusakan didarat dan dilaut disebabkan perbuatan tangan manusia, supaya Allab merasakan kepada mereka sebagian dari akibat perbuatan mereka, agar mereka kembali kejalan yang benar".

Berkaitan dengan terjadinya krisis SDA ini yang dikaitkan dengan laju pertumbuhan penduduk, terjadi polarisasi pendapat yakni clengan munculnya pandangan optimis disatu sisi, dan pandangan pesimis di sisi lain. Bagaimana kedua pandangan tersebur dalam menyingkapi keberadaan SDA, dam pandangan mana yang notabene lebih arif?

\section{Kontradiksi antara Pandangan Optimis dan Pesimis}

Eksistensi SDA dikaitkan dengan kemungkinan timbulnya krisis dan peningkatan jumlah penduduk pada abad 21 merupakan perdebatan yang tak kunjung habis antara kubu pandangan optimis dan pesimis.

Pandangan optimis mengasumsikan sama sekali tidak akan terdapat krisis sehubungan dengan pertambahan jumlah penduduk yang dikaitkan dengan SDA. Beberapa pemikiran yang melandasi pandangan optimis addalah sebagai berikut :

a. Banyak bagian dimuka bumi yang masih belum dihuni oleh manusia secara padat.

b. Banyak bagian bumi yang memiliki penduduk yang lebih padat di masa lalu dibanding masa kini. Tentunya bagian tersebut akan dapat menampung lebih banyak penducluk cli masia yang akan datang.

c. Sumnber alam tak akan pernah habis, oleh karena itu ticlak perlu dilinclungi clan diawetkan pemakaiannya.

d. Perkembangan ilmu pengetahuan dan tekhnologi tidak akan pernah berhenti, oleh kasren itu eksistensi SDA akan terus terjamin.

e. Berdasarkan butir a sampai d, maka populasi manusia boleh terus meningkat setinggi-tingginyal sesuai keinginan manusial sendiri.

Mereka yang mempunyai pandangan pesimis menganggap pemikiran yang melandasi pandangan optimis sebenarnyal sangat rapuh clan berangkat dari suatu kebingungan belaka. Satu faktal yang cliabaikan oleh pandangan optimis aclalah terjadinya berbagai kerusakan alam. Krisis SDA pasti akan muncul sehubunngan partambahan jumlah penduduk yang tidak terkendali. Pandangan pesimis mempunyai alasanyang kuat dan faktual yaitu sifat manusia yang mampu mengubah sifat dan kimia planet bumi. Sifat tersebutr seolah-olah merupakan "penerimain hipotesis' malaikat padal salat Allah menganugerahkan tugas kekhalifahan kepada manusia, yakni "mengapa menjadikan manusia sebagai kbalifab di bumi, padabal mereka adalah makbluk yang potensial sekali berbuat kerusakan dan pertumpaban darab?" (Q.S. Al- Baqarah 30).

Dari fakta-fakta yang alda, mungkin sángat setuju kalau kita berpendapat bahwa kecenderungan umum yang merisaukan laju peertumbuhan penduduk adalah suatu sikap yang lebih bijaksana dalam menyongsong hari esok di tengah-tengah situasi yang tidak menentu. Kecenderungan umum ini sebenarnya dilandasi oleh banyak akibat berantai yang sangat potensial. Sallah satu akibatnyal yang paling mendasar adlalah berkenaan dengan masalah pengadaan berbagai kebutuhan manusia, terutama kelancaran pengaddainnya.

\section{Pengertian dan Pembagian SDA}

Banyak sekali pendapat yang mencoba menjelaskan pengertian sumber daya alam. Seperti yang dikemukakan Ireland (dalam Syamsuri, 1995) bahwa SDA adalah suatu keaddain lingkungan alam (natural environmient) yang memiliki nilai untuk memenuhi kebutuhan hidup manusia. Sedangkan Isard (dalam Syamsuri, 1995) mendefinisikan SDA sebagai suatu keadaan lingkungan dan bahan-bahan mentah yang digunakan untuk memenuhi kebutuhannya dan memperbaiki kesejahteraanya. Dengan demikian dapat dikatakan bahwa SDA adalah semua unsur tata lingkungan biofisik yang dengan nyatta attau potensial dapat memenuhi kebutuhan manusia. Secaral singkat dapat dikatakan SDA adalah semua bahan (materi), yang terdapat di alam, yang 
clapat dimanfaatkan (dibutuhkan) untuk kepentingan hidup manusia.

Sumber daya alam dapat digolongkan menjadi beberapa kelompok berclasarkan beberapa kriteria. Katili (dalam Astina, 1994) membagi SDA menjaclihasil (produk) dan keadaan (situasi). Hasil (produk) meliputiRenewable Resources (dapat diperbaharui) dan Non-Renewable Resouces (tidak dapat diperbaharui). Contoh keaclaan (situasi) antara lainberupa air terjun, tubuh tanah. Soeriatmadja (1981) mengatakan bahwa status keaclaan sumber alam digolongkan ke dalam empat kattegori yang eliputi lautan, daratan dan makanan, bahan mineral, clan bahan bakar. Sedangkan Rivai (dalam Corebima, 1984) membagi SDA menjadi tiga macam yang terdirisumber daya insani (human resouces), sumber daya fisik, clansumber daya buatan. Sumber claya insani berupa kuantitas dan kualitas pengetahuan dan keterampilan manusia serta kebudayaan manusia. Sumber daya fisik terdiri clari SDA non-hayati clan SDA hayati. Yang perlu diperhatikan pula, SDA sebenarnya bukan hanya berupa materi dan energi saja, melainkan termasuk pula ruang, waktu, dan keanekaragaman.

Dari berbagai pembagian SDA tersebut, pembagian yang sering dipergunakan adalah pembagian adalah pembagian menurut Katili yakni SDA yang dapat diperbaharui (Renewable Resources) dan SDA yang tidak clapat diperbaharui (Non-Renewable Resources).

\section{Hubungan SDA, Manusia, dan Ekosistem}

Adakah hubungannya antara SDA dengan ekosistem? bagaimana pula hubungan antara SDA dengan manusia? Apakah antara SDA, manusia dan ekosistem terdapat hubungan? Bagan hubungan komponen ekosisitem dibawah ini dapat menjawab pertanyaan tersebut.

Faktorkkomponen biotik: Tumbuhan, hewan (termasuk manusia)
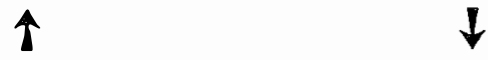

Fakłorkomponen a biotik : Sinar, air, udara, tanah, dsb.
Antara abiotik clan biotik terdapat hubungan timbal balik. Hubungan timbal balik antara jasad hidup dengan benda mati yang terdpat dlam suatu sistem (lingkungan) disebut dengan Ekosistem. Pada bagan cliatas, faktor/ komponen abiotik tergolong ke clalam SDA non- hayati. Sebaliknya faktor/komponen biotik tergolong dalam SDA hayati dan SDA insani. Yang perlu ditegaskan disini, bahwa manusia adalah bagian yang tak terpisahkan dari ekosistem, bukan merupakan sistem tersendiri atau diluar sistem. Oleh karena itu, manusia sesungguhnya adalah komponen tak terpisahkan dari ekosistem maupun SDA.

Dengan demikian sangat jelas bahwa antara ekosistem dengan SDA termasuk manusia di clalamnya terdapat hubungan yang sangat erat, yakni SDA adalah keseluruhan yang utuh dari ekosistem dalam kedudukan sebagai faktor atau komponen. Akibatnya, sesuatu kerusakan yang terjadi pada ekosistem sama saja artinya dengan keerusakan SDA, demikian pula sebaliknya.

\section{Manfaat SDA bagi Manusia}

Di dalam Al-Qur'an Surat Al-Baqarah 29 disebutkan "Dialab Allab yang menjadikan segala yang ada di bumi untuk kamu".Implikasi clari ayat ini adalah selama hiclupnya, manusia selalu menerima subsidi materi dan energi yang termasuk SDA dari lingkungannya. Beberapa contoh konkrit untuk hal ini antara lain eksistensi bahan pangan, bahan sandang dan bahan papan adalah produk tumbuhan dan hewan. Tumbuhan terutama ticlak clapat lepas clari eksistensi sinar matahari, talnah, air, udara, clan sebagainya. Demikian pula kebutuhan akan energi, adalah berasal dari produk tumbuhan dan hervan. Kebutuhan lain seperti kebutuhan akan estetika diperoleh dari tumbuhan, hewan ataupun. SDA nonhayati.

Sehubungan dengan hal diatas, adalah sangat benar apabila clikatakan bahwa manusia dapat mempertahankan keberadaanya di planet bumi hingga saat ini karena ketersediaan SDA. Termasuk pula masa depan (kelangsungan) keberadaan manusia mutlak tergantung pada subsidi materi dan energi (SDA). 
Dengan demikian sangat jelas bahwa SDA sangat dibutuhkan obeh manusia climasal lalu, sekarang dan yang akan datang. Ancaman terhadap keberadalan dan kelangsungan SDA sama saja artinya terhaclap keberadaan dan kelangsungan SDA sama sajajartinyà dengan ancaman terhadap keberadain dan kelangsungan hiclup manusia.

\section{Perkembangan Penduduk dan Keterbatasan SDA}

Kehiclupan manusia selalu terkait clengan berbagai macam kebutuhan, dengan jenis clan jumlah yang terus meningkatt. Astina (1994) mengatakan semakin maju peradapan, semakin meningkat pula kebutuhan manusia clalam berbagai aspek. Oleh kalrena itu, walaupun manusia adalah salah satu SDA, namun apabila laju pertumbuhan populasinya ticlak terkendali, maka akan menjadi masăalah bahkaın beban.

Malsalah yang akan timbul aclalah berhubungan clengan sifalt SDA clan kemampuan manusia untuk mengubah sifat fisika dan kimia planet bumi. Ada SDA yang dapat diperbaharui clan acla jugal yang ticlak dapat diperbahararui. Bagi SDA yang dapat diperbahararui sekalipun, jumlah penducluk yang amat meningkat tetap clapat menjacli beban, sebab clapat terjacli konumsi jauh melampaui jumlah yang tersedia. Hal ini sesuali dengan yang clikemukakan Odum (1971) bahwa lingkungan dan SDA mempunyai daya dukung tertentu, yakni suatu jumlah populasi yang optimal sehingga lingkungan dan SDA clapat memenuhi kebutuhan manusia clan makhluk hiclup dallam jangka panjang. Daya clukung tersebut pada suatu salat akan mencapai titik jenuh atau maksimal, yang berarti lingkungan SDA suclah tidak mampu lagi mendukung jumlah populasi yang berada di dalamnya.

Masailah penduduk clan SDA ini akan semakin rumit, manakala di jumpai ternyata masalah kependudukan bukan semata-mata masalah jumlah salja, melainkan kemiskinan, pendidikan, dan masalahmasailah lain (Brundtland et al..1988). Oleh karenal itu', pemecahannya ticlak clapat hanya dengan menganclalkan penekanan laju pertumbuhan penducluk sajja.

Beberapá tindakan antara lain perkembangan inclustri di sekitar kota menyebabkan banyak kalwasàn pemukiman 'menelan' daerah tepi kotal yang sàngat subur untuk usaha pertanian, pembuangan limbah melebihi kecepatan dekomposisi sehinggal menyebabkan terjaclinya polusi. Termasuk pula 'penyeragaman' wilayah claratan sebagai claerah pertanian clengan jalan menanam jenis tanaman pertanian yang serupa, sejenis, sevarietas, atalu seklon untuk wilayah yang sángat luals, dimana kondisi seperti ini sangat mendukung untuk timbulnyal 'ledakan ' populasi hama clan penyakit.

Tindakan-tinclakan diatas, tanpa clisaclari sebenarnya aclalah tinclakan mengabaikan SDA ruang, waktu, dan keanekaragaman. SDA tersebut cenclerung terabalikan, karena pacla umumnyal orang hanyà mengenál SDA sebagai matteri clan energi salja. Dengan uralian tersebut, sangat jelass, bahwa SDA adalah sesuatu yang terbatals, yang harus dikelola dengan sebaik-sebaiknyal agar manfalt clan keberaclaannya berkelanjutan, ticlak sekeclar climanfalatkan sajja tanpá langkanh memproduksi.

\section{Pemanfaatan dan Pengelolaan SDA}

Berbagali kelebihan yang diberikan Allah kepadal manusia clari pacda organisme lain, bukanlah untuk merusalk lingkungan dan SDA, melainkan harus dimanifestasikan clalam bentuk tanggung jawab pengelolalan. Allah berfirman "Diatelah menciptakan kamu dari bumi (tanab) dan menjadikan kamu sebagai pemakmurannya" (Q.S. Hud:61). Dalam kaitan ini sebagai pengelola alam, bukan sekedar sebagai pemanfalatan alam belaka. Sebab pemanfaat clapat bermakna pengekploitasi SDA clengan sebasálrbesarnyà.

Secara ekonomi, pemanfalatan SDA sangalt mempunyai nilai ekonomis, karena terkandungal prinsip dengan pengeluaran sekecil-kecilnya untuk memperoleh hasil yang sebesar-besarnya. Namun pemikiran semacam ini aclalah pemikiran yang parsial. Secaral ekonomi memang menguntungkan, namun haya sesalat atau ticlak berkelanjutan. Sebaliknya dengan pengelolalan SDA, terkanclung makna pemeliharalan untuk dapat diperoleh manfalat yang berkelanjutan. Dengan pengelolalan diharapkan tercapai suatu keseimbangan antara kepentingan 
ekonomis dengan kepentingan ekologis, nilai ekonomis akan diperoleh jauh lebih besar daripalda sekedar eksploitasi belakal.

Berdasarkkan hal ini, maka pengelolaan SDA perlu memperhatikan beberapa hal seperti perlindungan SDA dari kepunahan, penghematan pemakaian SDA secara keseluruhan, peningkatan pemakaian materi dan energi (serta macam-macam SDA yang lain), perbaikan keseimbangan distribusi pemanfaatan SDA ruang, perbaikan pemakaian SDA waktu (agar proses resiklus berjalan lancar), penganekaragaman pemakalian macam-macam alternatif sumber daya untuk suatu kebutuhan.

Selain berbagai upaya pengelolaan SDA seperti yang clikemukakan diatalas, tidak banyak mempunyai erti bila tidak diperhatikan pula hal-hal lain seperti pengembangan teori ekonomi yang didasarkan atals keseimbangan dan bukan atals dasalr pertumbuhan, pengendalian laju pertumbuhan pencluduk, dan perbaikan kualitas pendidikan, sebab bagaimanapun perbaikan pendidlikan adalah sesuatu yang sangall funclamental.

Perbaikan dan pengembangan pendidikan ini terutama pada pendidikan agama (Islam khususnya), sebab Islam ticlak sekedar mengatur bagaimana persiapan kehiclupan cli akhirat, namun merupakan agama yang paling komprehensif clalam mengatur tatanan kehiclupan cli alam termasuk pula calam mengatur konservasi SDA. Dalam Q.S. Al-Qashash 77 Allah memberikan statemen bahwa Dia sangat menyukai orang-orang yang membuat kerusakan di muka bumi.

\section{Penutup}

Islam adalah pembawa rahmad bagiseluruh alam (Rahmatan lil-'alamin), dan telah memberikan tuntunan dan ajaran yang luas agar umat manusia mermpunyai tanggung jawab moral terhadap konservasi SDA. Di clalam Al-Qur'an, Allah s.w.t melarang umat manusia membuat kerusakan dimuka bumi, clemikian pula pesan Rasulullah SAW mengajarkan untuk berbuat baik terhadap sesama manusia, terhadap flora clan fauna. Rasulullah telah meletakkan clasar-clasar prinsip hidup yaitu keseimbangan antara kepentingan manusia clan SDA atau kepentingan ekonomis dengan ekologis, serta keseimbangan antara kehiclupan duniawi clan ukhrawi.

Oleh karena itu, konservasi SDA yang berintikan pengelolatan SDA, adlalah suatu hal yang mutlak harus clilaksanakan dan menjadi tanggung jawab utama manusia sebagai khalifah di bumi ini. Ada tigal tugas utama bagi manusia berkaitan dengan koservasi SDA meliputi Al-Intifa' (memelihara clan menclayagunakan), Al-I'tibar (memikirkan, mensyukuri, menggali rahasial alam), dan Al-Islah (memelihara dan sengaja kelestarian untuk kemslahatan umat, sertal terciptanyal harmoni kehidupan alam ciptalan Allah s.w.t.)

\section{Bahan Bacaan}

Astina, I Komang. 1994. Sumber Dayal Alam. Makalah disajjikan daalam Semilokal KLH Guru SMU se Jatim, PKPKLH-Lemlit IKIP Malng, Malang, 9-10 September.

Brundtland, Gro Harlem et al. 1988. Harri Depan Kita Bersama:

Komisi Dunia untuk Lingkungan clan Pembangunan (The World Commission on Environment and Develpment). Jakarta : PT. Gramedial.

Corebima, A.D. 1984. Sumber Dayal Alam. Makalah clisajijakn dalam Diklat Kelompok Pecinta Alam IKIP Malang, Malang, tanggal (?)

Harahap, Aclnan, dkk. 1997. Islam dlan Lingkungan Hidlup. Jakarta : Yayalsan Swarna Bhumy.

Odum, E.P. 1971. Fundlamentals of Ecology (3rd ed.). Philadelphia, London, Toronto: W.B. Saunder Company.

Soeriaatmadjal, R.E. 1981.Ilmu Lingkungan. Bandung: Penerbit ITB.

Surin, Bachtiar. 1978. Teriemalh \& Talfsir Al-Our'an. Bandung : Fá. Sumatrai.

Syamsuri, Istamar. 1295.Sumber Dayya Alam, Manfaat dan Pelestariannyá. Makalah clisajikan clalam Semilokal PLH Dosen PTN-PTS se Jatim \& Jateng, PKPKLH-Lemlit IKIP Malangh, Malang, 10-13 Juli.

Tim Perunus Fak. Teknik UMJ Jakarta. 1998. Al-Islam \& IPTEK. Jakarta: PT RajaGrafindo Persada. 